\title{
The Treatment of Peripheral Vestibular Dysfunction Using Caloric Vestibular Stimulation in Patients with Cerebral Hypertensive Crisis
}

\author{
Yana Yuriyvna Gomza1, Ralph Mösges ${ }^{2 *}$ \\ ${ }^{1}$ Otorhinolaryngology Department, National O.O. Bogomolets Medical University, Kiev, Ukraine \\ ${ }^{2}$ Institute of Medical Statistics, Informatics and Epidemiology, University Hospital of Cologne, Cologne, \\ Germany \\ Email: ralph@moesges.de
}

Received 20 April 2015; accepted 10 May 2015; published 18 May 2015

Copyright (C) 2015 by authors and Scientific Research Publishing Inc.

This work is licensed under the Creative Commons Attribution International License (CC BY). http://creativecommons.org/licenses/by/4.0/

(c) (i) Open Access

\begin{abstract}
Background: To verify the efficacy of caloric vestibular stimulation in patients with peripheral vestibular dysfunction after cerebral hypertensive crisis. Methods: Enrolled in the study were 60 patients with peripheral vestibular dysfunction caused by a cerebral hypertensive crisis, documented by vestibulometry. Thirty patients underwent standard treatment plus caloric vestibular stimulation, and 30 control group patients received standard treatment alone. Results: After the two-week treatment course, the sensation of vertigo was observed in $40.0 \% \pm 8.9 \%$ of treatment group patients compared with $80.0 \% \pm 7.3 \%$ of control group patients $(t=3.46 ; p<0.001)$. Spontaneous vestibular somatic reactions were found in $46.7 \% \pm 9.1 \%$ of the study treatment group in contrast to $86.7 \% \pm 6.2 \%$ of the control group $(t=3.63 ; p<0.001)$. Spontaneous nystagmus was seen in $40.0 \% \pm 8.9 \%$ of treatment group patients compared with $93.3 \% \pm 4.6 \%$ of control subjects $(t=5.31 ; p<0.001)$. Spontaneous vestibular vegetative reactions were observed in $33.3 \% \pm$ $8.6 \%$ of patients receiving study treatment in contrast to $93.3 \% \pm 4.6 \%$ of control group patients $(t=6.16 ; p<0.001)$. Also, $53.3 \% \pm 9.1 \%$ of study treatment group patients showed asymmetry of labyrinths compared with $86.7 \% \pm 6.2 \%$ of patients from the control group $(t=3.03 ; p<0.001)$. Conclusion: Caloric vestibular stimulation was shown to be an effective treatment for peripheral vestibular dysfunction in patients with cerebral hypertensive crisis. During the 14-day treatment of cerebral hypertensive crisis, complete labyrinthine function recovery occurred in $46.7 \%$ of treatment group patients who underwent caloric vestibular stimulation as opposed to $13.3 \%$ of control group patients who received standard treatment alone.
\end{abstract}

${ }^{*}$ Corresponding author.

How to cite this paper: Gomza, Y.Y. and Mösges, R. (2015) The Treatment of Peripheral Vestibular Dysfunction Using Caloric Vestibular Stimulation in Patients with Cerebral Hypertensive Crisis. International Journal of Otolaryngology and Head \& Neck Surgery, 4, 229-235. http://dx.doi.org/10.4236/ijohns.2015.43039 
Keywords

Peripheral Vestibular Dysfunction, Cerebral Hypertensive Crisis, Labyrinthine Function

\section{Introduction}

Cerebral hypertensive crisis constitutes one of the most frequent cerebrovascular diseases, comprises $13 \%-15 \%$ of all acute brain vascular disorders, and is found in two-thirds of patients with transient vascular disorders of the brain. Patients affected by it most often complain of headache accompanied by nausea, vomiting, and episodes of unconsciousness. Vestibular dysfunction in general is one of the earliest and most frequent manifestations, having different cerebrovascular pathologies. The early phylogenetic formation of the vestibular system makes it highly sensitive to external and pathogenic influences. Hearing impairment has also been observed in such patients. The inner ear consists of the hearing organ, the cochlea, which is joined topographically, anatomically, and functionally to the vestibular apparatus (vestibule and semicircular channels) [1]-[16].

Caloric vestibular stimulation (CVS) has traditionally been used as a tool for neurological diagnosis. It is a routine diagnostic technique applied in the neurological assessment of vestibular function and brain death [17][22]. However, CVS has also been applied effectively in the treatment of patients with certain neurological disorders [20] [22]-[32].

The aim of this randomized, controlled study was to verify the efficacy of CVS in patients with peripheral vestibular dysfunction after cerebral hypertensive crisis.

\section{Material and Methods}

Sixty patients with peripheral vestibular dysfunction after cerebral hypertensive crisis were randomized into two patient groups. The study treatment group results were compared with those of the control group. Patients received inpatient treatment with CVS in the Otorhinolaryngology Department and the Neurology Department of the National O.O. Bogomolets Medical University, Ukraine. The trial study was provided as a part of scientific work of the Otorhinolaryngology Department of Bogomolets National Medical University, registration number 0113U007334. The study took place from March 2012 to September 2013 and was approved by the local ethics committee. Each participant signed an informed consent form.

The study treatment group comprised 30 patients aged 29 to 57 years, the average age being $47 \pm 1$ years. Sixteen patients were female and 14 were male. The average duration of disease prior to study enrollment was 6 \pm 1 days. The control group included 30 patients who were 29 to 59 years old, the average age being $47 \pm 2$ years. Nineteen patients were female and 11 were male. The average duration of disease prior to study enrollment was $6 \pm 1$ days. All patients were subjected to an obligatory general clinical examination which included endoscopy. Only patients with no history of pathological changes to otorhinolaryngological organs were included in the investigation. All examined patients exhibited increased arterial pressure during cerebral hypertensive crisis, with an average systolic arterial pressure level of $169 \pm 6 \mathrm{~mm} \mathrm{Hg}$. Neurologists applied the following brain hemodynamic examination methods to determine the main diagnosis of cerebral hypertensive crisis: rheoencephalography, electroencephalography, transcranial Doppler ultrasonography, nuclear magnetic resonance (NMR) imaging of the brain, and brain spiral computer tomography.

Vestibulometric examinations were conducted in the Otorhinolaryngology Department at the National O.O. Bogomolets Medical University, Ukraine. Such examinations were repeated in the study treatment group of 30 patients two weeks after beginning CVS. Patients from both groups also received standard medical therapy for cerebral hypertensive crisis. The study treatment group results were compared with the results of 30 control group patients who did not receive CVS, but instead underwent only standard therapy for cerebral hypertensive crisis.

The CVS method included external ear channel irrigation using $60 \mathrm{ml}$ of cold water at $25^{\circ} \mathrm{C}$ for $10 \mathrm{~s}$ once daily over a course of 10 days.

Instrumental methods, i.e., the methods of vestibular examination, consisted of: walking tests (walking along a path; flanking walk), Fukuda writing test, Fukuda stepping test, past-pointing test, finger-nose test, cephalography (the method of evaluating the quantity evaluation of balance, when a stationary apparatus is fixed at the 
patient's head and registers imbalance by calculating the cephalography index (the higher the index, the higher the level of imbalance)), Barany's rotating chair test, vestibular illusion of counterrotation test, caloric test, and electronystagmography (the study of spontaneous, positional nystagmus).

The statistical analysis was carried out using the statistics program SPSS 16.0. The results for the sensation of vertigo, spontaneous vestibular somatic reactions, spontaneous nystagmus, spontaneous vestibular vegetative reactions, and asymmetry of labyrinths were described using the following statistical parameters: mean, standard deviation, confidence interval $95 \%$, median, 25 th and 75 th percentiles. The difference in the outcomes between the treatment groups was found to be significant using the Student's t-test $(\mathrm{p}<0.01)$. The regressive analysis of the $\mathrm{X}$ and $\mathrm{Y}$ variables resulted in the linear dependency $\mathrm{Y} \sim \mathrm{B} * \mathrm{X}$, where $\mathrm{X}$ and $\mathrm{Y}$ are the certain variables and $\mathrm{B}$ is the certain real number.

\section{Results}

Before treatment, the sensation of vertigo was recorded in $100 \%$ of the examined patients from both groups. Patients described the sensation of objects rotating around them or the sensation of their body rotating in one definite direction. During the antirotative vestibular illusion test, the average reaction period lasted $24 \pm 3 \mathrm{~s}$ in the study treatment group and $25 \pm 4 \mathrm{~s}$ in the control group. Under the vestibular illusion of counterrotation test, reaction period asymmetry was registered in $14(46.6 \%)$ patients from the study treatment group and $15(50.0 \%)$ from the control group.

The sensation of vertigo was noted after treatment in $12(40.0 \%)$ patients from the study treatment group compared to $24(80.0 \%)$ patients from the control group. The average reaction period under the antirotative vestibular illusion test lasted $18 \pm 10 \mathrm{~s}$ in the study treatment group and $23 \pm 9 \mathrm{~s}$ in the control group. Reaction period asymmetry under the vestibular illusion of counterrotation test persisted in $5(16.6 \%)$ patients from the study treatment group and 10 (33.3\%) from the control group.

Prior to treatment, all patients from both groups exhibited balance disturbances in the walking tests, Fukuda writing test, Fukuda stepping test, past-pointing test, finger-nose test, and in cephalography. During the Fukuda stepping test, imbalance manifesting as rectilinear body movement was observed in all patients, with the average value being $149 \pm 14 \mathrm{~cm}$ in the study treatment group and $146 \pm 16 \mathrm{~cm}$ in the control group. Imbalance in the form of body rotation was observed in all patients, with an average value of $92^{\circ} \pm 12^{\circ}$ in the study treatment group and $91^{\circ} \pm 14^{\circ}$ in the control group.

Spontaneous vestibular somatic reactions were observed in $14(46.7 \%)$ patients after undergoing CVS as compared to $26(86.7 \%)$ control group patients. The average pathologic deviation obtained in the Fukuda stepping test was $112 \pm 12 \mathrm{~cm}$ in the study treatment group and $123 \pm 12 \mathrm{~cm}$ in the control group. During this test, an abnormal body rotation angle was observed in the patients, with an average value of $45^{\circ} \pm 14^{\circ}$ in the study treatment group and $62^{\circ} \pm 12^{\circ}$ in the control group.

Before treatment, all patients from both groups showed significant vestibular somatic reactions, such as the appearance of spontaneous, positional nystagmus, which were recorded via electronystagmography. Visually determined spontaneous nystagmus was observed in 29 (96.6\%) patients from the study treatment group. In 20 $(66.6 \%)$ of these patients, it was horizontal and of the first stage of intensity, and in $9(30.0 \%)$ patients the nystagmus was horizontal, of middle-level amplitude, and of the second stage of intensity. After conducting electronystagmography, spontaneous nystagmus was diagnosed in all patients from both groups. Positional nystagmus was also documented in all patients. Positional nystagmus combined with nonpermanent dizziness affected by moving or shaking the head was registered in $6(20.0 \%)$ of the patients receiving study treatment. Irregular, unstable positional nystagmus was recorded in $24(80.0 \%)$ study treatment patients.

Spontaneous and positional nystagmus was observed in $12(40.0 \%)$ patients receiving study treatment compared to 28 (93.3\%) control group patients after treatment.

Vestibular vegetative reactions were observed before treatment in all patients from both groups in all irritative tests: Barany's rotating chair test, vestibular illusion of counterrotation test, and caloric test. Spontaneous vestibular vegetative reactions were observed in $10(33.3 \%)$ patients from the study treatment group after applying CVS and in 28 (93.3\%) patients from the control group.

Before treatment, the reaction period asymmetry under Barany's test was documented in $15(50.0 \%)$ patients from the study treatment group, with an average reaction period of $9 \pm 1 \mathrm{~s}$, and in $15(50.0 \%)$ control group patients, with an average reaction period of $8 \pm 1 \mathrm{~s}$. After treatment, the reaction period asymmetry under Barany's 
test was registered in 8 (26.6\%) patients from the study treatment group, with the average duration of Barany's reaction period being $16 \pm 1 \mathrm{~s}$, and in $12(50.0 \%)$ patients from the control group, with the average duration of Barany's reaction period being $12 \pm 1 \mathrm{~s}$.

The most informative method of determining inner ear function was the caloric reflex test (i.e., CVS) because it permitted examinations of the ears separately. Patients in the study treatment group received cold $\left(25^{\circ} \mathrm{C}\right)$ and warm $\left(39^{\circ} \mathrm{C}\right)$ irrigation courses of the external ear channels.

During the experimental nystagmus examination under load reactions in the caloric reflex test (i.e., CVS), asymmetry of the labyrinths was shown to exist in all cases before treatment. Hyperreflection of the labyrinths was observed in $10(33.3 \%)$ patients from the study treatment group and in $9(30.0 \%)$ patients from the control group. Hyporeflection was seen in the other $20(66.6 \%)$ study treatment patients and in $21(70.0 \%)$ control group patients.

Labyrinthine function returned to normal after CVS. Asymmetry of the labyrinths was observed in 16 (53.3\%) patients in the study treatment group and in $26(86.7 \%)$ patients in the control group. Hyperreflection of the labyrinths was present in $5(16.7 \%)$ patients from the study treatment group and in $8(26.7 \%)$ patients from the control group. Hyporeflection was seen in another 11 (36.7\%) treatment group patients and in $18(60.0 \%)$ control group patients.

In patients with vestibular dysfunction after cerebral hypertensive crisis, the results from the vestibular apparatus function examination of patients who had undergone two weeks of CVS showed significant improvement in the indices of all vestibulometric tests compared to the results of the control group patients.

The sensation of vertigo, spontaneous vestibular somatic reactions, spontaneous nystagmus, spontaneous vestibular vegetative reactions, and asymmetry of the labyrinths were the main indices of vestibulometry, which was used to determine the vestibular function of the labyrinths (Table 1 ).

Thus, the sensation of vertigo was observed in $40.0 \% \pm 8.9 \%$ of patients from the study treatment group compared to $80.0 \% \pm 7.3 \%$ of patients from the control group $(t=3.46 ; t>3 ; p \leq 0.001)$. Spontaneous vestibular somatic reactions were reported in $46.7 \% \pm 9.1 \%$ of patients from the study treatment group compared to $86.7 \% \pm 6.2 \%$ of control group patients $(\mathrm{t}=3.63 ; \mathrm{t}>3 ; \mathrm{p} \leq 0.001)$. Spontaneous nystagmus was documented in $40.0 \% \pm 8.9 \%$ of patients from the study treatment group in comparison to $93.3 \% \pm 4.6 \%$ of control group patients $(\mathrm{t}=5.31 ; \mathrm{t}>3 ; \mathrm{p} \leq 0.001)$. Spontaneous vestibular vegetative reactions were seen in $33.3 \% \pm 8.6 \%$ of patients receiving the study treatment in contrast to $93.3 \% \pm 4.6 \%$ of patients from the control group $(\mathrm{t}=6.16 ; \mathrm{t}>$ $3 ; \mathrm{p} \leq 0.001)$. Asymmetry of the labyrinths was reported in $53.3 \% \pm 9.1 \%$ of patients from the study treatment group compared to $86.7 \% \pm 6.2 \%$ of patients from the control group $(t=3.03 ; \mathrm{t}>3 ; \mathrm{p} \leq 0.001)$. Thus, an absence of inner ear dysfunction was documented in $46.7 \% \pm 9.1 \%$ of study treatment group patients compared to $13.3 \% \pm 6.2 \%$ of control group patients $(\mathrm{t}=3.03 ; \mathrm{t}>3 ; \mathrm{p} \leq 0.001)$.

\section{Discussion}

After analyzing the results, we agree with other authors about the effects of CVS in a wide range of contexts in

$$
\text { Table 1. Main indices of vestibulometry after two-week application of caloric vestibular stimulation or standard therapy. }
$$

\begin{tabular}{|c|c|c|c|c|c|c|c|}
\hline \multirow{2}{*}{ Indices of vestibulometry } & \multicolumn{2}{|c|}{ Percentage of patients with disorder, $P$} & \multirow{2}{*}{$\begin{array}{l}\text { Disparity } \\
\text { P1 - P2* }\end{array}$} & \multirow{2}{*}{ p1* } & \multirow{2}{*}{ p2* } & \multirow{2}{*}{$t^{*}$} & \multirow{2}{*}{ p-value } \\
\hline & Study treatment group & Control group & & & & & \\
\hline Sensation of vertigo & 40.0 & 80.0 & 40.0 & 8.9 & 7.3 & 3.46 & $<0.001$ \\
\hline Spontaneous vestibular somatic reactions & 46.7 & 86.7 & 40.0 & 9.1 & 6.2 & 3.63 & $<0.001$ \\
\hline Spontaneous nystagmus & 40.0 & 93.3 & 53.3 & 8.9 & 4.6 & 5.31 & $<0.001$ \\
\hline Spontaneous vestibular vegetative reactions & 33.3 & 93.3 & 60.0 & 8.6 & 4.6 & 6.16 & $<0.001$ \\
\hline Asymmetry of labyrinths & 53.3 & 86.7 & 33.4 & 9.1 & 6.2 & 3.03 & $<0.001$ \\
\hline Absence of inner ear dysfunction & 46.7 & 13.3 & 33.4 & 9.1 & 6.2 & 3.03 & $<0.001$ \\
\hline
\end{tabular}

*P1: Percentage of study treatment group of patients with vestibular dysfunction in cerebral hypertensive crisis after the two-week application of CVS. P2: Percentage of control group of patients with vestibular dysfunction in cerebral hypertensive crisis after the two-week application of standard therapy. p1: Mean error of P1. p2: Mean error of P2. t: Reliability criterion. 
the cognitive and clinical neurosciences [20] [24]-[26] [29]-[35]. CVS represents a unique experimental method for use in neurophilosophical studies. Its reported phenomenological effects are of great interest for the study of brain activity, which is important to better understand the activation processes of brain structures [4] [20] [36]. However, after analyzing the results of treatment with CVS, we also observed the effective improvement of labyrinthine function in patients with vestibular dysfunction after cerebral hypertensive crisis: the vestibular apparatus (receptor organ) and the central vestibular pathway function were repaired. Labyrinthine asymmetry was present in $53.3 \% \pm 9.1 \%$ of patients who had undergone CVS as opposed to $86.7 \% \pm 6.2 \%$ of patients who had received standard therapy alone. The results of the investigation described here showed that CVS effectively improved labyrinthine function in patients with vestibular dysfunction after cerebral hypertensive crisis.

The mechanism by which peripheral labyrinthine function improved after CVS may be explained as the result of the activation of the entire vestibular apparatus, i.e., the inverse response of the brain to the irritated peripheral receptors. It seems reasonable to presume that vestibular stimulation leads to the interaction between the somatosensory system and the vestibular apparatus [33] [34] [37]-[41]. It is necessary to mention that all this has given rise to considerable controversy, as it is a hypothesis and is still being studied. We agree with other authors who maintain that the routine application of CVS would provide, at least in theory, a more complete assessment of the inner ear and brain processes [20]. It would be of great interest and possibly open new perspectives in the field if investigators also applied this or other CVS methods in future studies.

\section{Conclusion}

Caloric vestibular stimulation was observed to be an effective treatment for peripheral vestibular dysfunction in patients with cerebral hypertensive crisis. This treatment method resulted in the complete recovery of labyrinthine function in almost half of all patients (46.7\%) who received it. In contrast, only 4 out of $30(13.3 \%)$ patients who underwent standard therapy experienced complete recovery of labyrinthine function. Our study results suggest that caloric vestibular stimulation should be prescribed to all patients with peripheral vestibular dysfunction after cerebral hypertensive crisis.

\section{Acknowledgements}

We would like to thank Gena Kittel and Marie-Josefine Joisten for their editorial assistance.

\section{References}

[1] Benoudiba, F., Toulgoat, F. and Sarrazin, J.L. (2013) The Vestibulocochlear Nerve (VIII). Diagnostic and Interventional Imaging, 94, 1043-1050. http://dx.doi.org/10.1016/j.diii.2013.08.015.

[2] Fujita, N., Yamanaka, T. and Hosoi, H. (2002) Usefulness of MR Angiography in Cases of Central Vertigo. Auris Nasus Larynx, 29, 247-252. http://dx.doi.org/10.1016/S0385-8146(02)00016-0.

[3] Gacek, R.R. (2008) A Place Principle for Vertigo. Auris Nasus Larynx, 35, 1-10. http://dx.doi.org/10.1016/j.anl.2007.04.002.

[4] Goycoolea, M., Mena, I. and Neubauer, S. (2009) Is There a Difference in Activation or in Inhibition of Cortical Auditory Centers Depending on the Ear That Is Stimulated? Acta Oto-Laryngologica, 129, 348-353. http://dx.doi.org/10.1080/00016480802495420.

[5] Kandel, E.R., Schwartz, J.H. and Jessell, T.M. (2000) Principles of Neuroscience. 4th Edition, McGraw-Hill, New York, 591-624.

[6] Koyuncu, M., Elhami, A.R., Alkan, H., Sahin, M., Basoglu, T. and Simsek, M. (2001) Investigation of the Vertebrobasilar Arterial System in Vertigo by Vestibulocochlear Test, SPECT and Angiography. Auris Nasus Larynx, 28, 23-28. http://dx.doi.org/10.1016/S0385-8146(00)00068-7.

[7] Lamontagne, A., Paquet, N. and Fung, J. (2003) Postural Adjustments to Voluntary Head Monitoring during Standing Are Modified Following Stroke. Clinical Biomechanics, 18, 832-842. http://dx.doi.org/10.1016/S0268-0033(03)00141-4.

[8] Lee, H. and Baloh, R.W. (2005) Sudden Deafness in Vertebrobasilar Ischemia: Clinical Features, Vascular Topographical Patterns and Long-Term Outcome. Journal of the Neurological Sciences, 228, 99-104. http://dx.doi.org/10.1016/j.jns.2004.10.016.

[9] Lonsbury-Martin, B.L., Martin, G.K. and Coats, A.C. (1985) The Physiology of the Auditory and Vestibular Systems. In: Ballenger, J.J., Ed., Diseases of the Nose, Throat, Ear, Head and Neck, 13th Edition, Lea and Febiger, Philadelphia, 
952-954.

[10] Mills, J.H., Khariwala, S.S. and Weber, P.C. (2006) Anatomy and Physiology of Hearing. In: Bailey, B.J., Johnson, J.T. and Newlands, S.D., Eds., Head \& Neck Surgery: Otolaryngology, 4th Edition, Vol. 2, Lippincott Williams \& Wilkins, Philadelphia, 1883-1903.

[11] Nakamichi, R., Yamazaki, M., Ikeda, M., Isoda, H., Kawai, H., Sone, M., et al. (2013) Establishing Normal Diameter Range of the Cochlear and Facial Nerves with 3D-CISS at 3T. Magnetic Resonance in Medical Sciences, 12, 241-247. http://dx.doi.org/10.2463/mrms.2013-0004

[12] Pagarkar, W. and Davies, R. (2004) Dizziness. Medicine, 32, 18-23. http://dx.doi.org/10.1383/medc.32.9.18.49908

[13] Pollak, L., Kushnir, M. and Stryjer, R. (2006) Diagnostic Value of Vestibular Evoked Myogenic Potentials in Cerebellar and Lower-Brainstem Strokes. Neurophysiologie Clinique, 36, 227-233. http://dx.doi.org/10.1016/j.neucli.2006.08.014

[14] Sooy, C.D. and Boles, R. (1980) Neuroanatomy for the Otolaryngologist-Head Neck Surgeon. In: Paparella, M.M., Shunrick, D.A., Gluckman, J.L. and Meyerhoff, W.L., Eds., Otolaryngology, 2nd Edition, Vol. I, W.B. Saunders Company, Philadelphia, 151-154.

[15] Tóth, M. and Csillag, A. (2005) The Organ of Hearing and Equilibrium. In: Cillag, A., Ed., Atlas of the Sensory Organs: Functional and Clinical Anatomy, Humana Press, Totowa, 1-83. http://dx.doi.org/10.1385/1-59259-849-8:001

[16] Yamasoba, T., Kikuchi, S. and Higo, R. (2001) Deafness Associated with Vertebrobasilar Insufficiency. Journal of the Neurological Sciences, 187, 69-75. http://dx.doi.org/10.1016/S0022-510X(01)00525-1

[17] Albernaz, P.L.M. and Ganança, M.M. (1972) The Use of Air in Vestibular Caloric Stimulation. The Laryngoscope, 82, 2198-2203. http://dx.doi.org/10.1288/00005537-197212000-00008

[18] Fasold, O., Von Brevern, M., Kuhberg, M., Ploner, C.J., Villringer, A., Lempert, T. et al. (2002) Human Vestibular Cortex as Identified with Caloric Stimulation in Functional Magnetic Resonance Imaging. Neuroimage, 17, 1384-1393. http://dx.doi.org/10.1006/nimg.2002.1241

[19] Fire, T.D., Tusa, R.J., Furman, J.M., Zee, D.S., Frohman, E., Baloh, R.W., et al. (2000) Assessment: Vestibular Testing Techniques in Adults and Children: Report of the Therapeutics and Technology Assessment. Subcommittee of the American Academy of Neurology. Neurology, 55, 1431-1441. http://dx.doi.org/10.1212/WNL.55.10.1431

[20] Miller, S.M. and Ngo, T.T. (2007) Studies of Caloric Vestibular Stimulation: Implications for the Cognitive Neurosciences, the Clinical Neurosciences and Neurophilosophy. Acta Neuropsychiatrica, 19, 183-203. http://dx.doi.org/10.1111/j.1601-5215.2007.00208.x

[21] (1995) Practice Parameters for Determining Brain Death in Adults (Summary Statement). The Quality Standards Subcommittee of the American Academy of Neurology. Neurology, 45, 1012-1014.

[22] Webb, C. (1985) COWS Caloric Test. Annals of Emergency Medicine, 14, 938. http://dx.doi.org/10.1016/S0196-0644(85)80671-5

[23] André, J.M., Martinet, N., Paysant, J., Beis, J.M. and Le Chapelain, L. (2001) Temporary Phantom Limbs Evoked by Vestibular Caloric Stimulation in Amputees. Neuropsychiatry, Neuropsychology, and Behavioral Neurology, 42, 190-196.

[24] Bisiach, E., Rusconi, M.L. and Vallar, G. (1991) Remission of Somatoparaphrenic Delusion through Vestibular Stimulation. Neuropsychologia, 29, 1029-1031. http://dx.doi.org/10.1016/0028-3932(91)90066-H

[25] Bottini, G., Paulesu, E., Gandola, M., Loffredo, S., Scarpa, P., Sterzi, R., et al. (2005) Left Caloric Vestibular Stimulation Ameliorates Right Hemianesthesia. Neurology, 65, 1278-1283. http://dx.doi.org/10.1212/01.wnl.0000182398.14088.e8

[26] Cappa, S., Sterzi, R., Vallar, G. and Bisiach, E. (1987) Remission of Hemineglect and Anosognosia during Vestibular Stimulation. Neuropsychologia, 25, 775-782. http://dx.doi.org/10.1016/0028-3932(87)90115-1

[27] Le Chapelain, L., Beis, J.M., Paysant, J. and André, J.M. (2001) Vestibular Caloric Stimulation Evokes Phantom Limb Illusions in Patients with Paraplegia. Spinal Cord, 39, 85-87. http://dx.doi.org/10.1038/sj.sc.3101093

[28] Mueller-Jensen, A., Neunzig, H.P. and Emskötter, T. (1987) Outcome Prediction in Comatose Patients: Significance of Reflex Eye Movement Analysis. Journal of Neurology, Neurosurgery \& Psychiatry, 50, 389-392. http://dx.doi.org/10.1136/jnnp.50.4.389

[29] Ramachandran, V.S. and McGeoch, P.D. (2007) Can Vestibular Caloric Stimulation Be Used to Treat Apotemnophylia? Medical Hypotheses, 69, 250-252. http://dx.doi.org/10.1016/j.mehy.2006.12.013

[30] Ramachandran, V.S., McGeoch, P.D. and Williams, L. (2007) Can Vestibular Caloric Stimulation Be Used to Treat Dejerine-Roussy Syndrome? Medical Hypotheses, 69, 486-488. http://dx.doi.org/10.1016/j.mehy.2006.12.036

[31] Rode, G., Charles, N., Perenin, M.T., Vighetto, A., Trillet, M. and Aimard, G. (1992) Partial Remission of Hemiplegia and Somatoparaphrenia through Vestibular Stimulation in a Case of Unilateral Neglect. Cortex, 28, 203-208. 
http://dx.doi.org/10.1016/S0010-9452(13)80048-2

[32] Vallar, G., Sterzi, R., Bottini, G., Cappa, S. and Rusconi, M.L. (1990) Temporary Remission of Left Hemianesthesia after Vestibular Stimulation. A Sensory Neglect Phenomenon. Cortex, 26, 123-131. http://dx.doi.org/10.1016/S0010-9452(13)80078-0

[33] Rossetti, Y. and Rode, G. (2002) Reducing Spatial Neglect by Visual and Other Sensory Manipulations: Noncognitive (Physiological) Routes to the Rehabilitation of a Cognitive Disorder. In: Karnath, H.O., Milner, D. and Vallar, G., Eds., The Cognitive and Neural Bases of Spatial Neglect, Oxford University Press, New York, 375-396. http://dx.doi.org/10.1093/acprof:oso/9780198508335.003.0027

[34] Rubens, A.B. (1985) Caloric Stimulation and Unilateral Visual Neglect. Neurology, 35, 1019-1024. http://dx.doi.org/10.1212/WNL.35.7.1019

[35] Utz, K.S., Korluss, K., Schmidt, L., Rosenthal, A., Oppenlander, K., Keller, I., et al. (2011) Minor Adverse Effects of Galvanic Vestibular Stimulation in Persons with Stroke and Healthy Individuals. Brain Injury, 25, 1058-1069. http://dx.doi.org/10.3109/02699052.2011.607789

[36] Neuman, A.C. (2005) Central Auditory System Plasticity and Aural Rehabilitation of Adults. Journal of Rehabilitation Research \& Development, 42, 169-186. http://dx.doi.org/10.1682/JRRD.2005.01.0020

[37] Bottini, G., Gandola, M., Sedda, A. and Ferrè, E.R. (2013) Caloric Vestibular Stimulation: Interaction between Somatosensory System and Vestibular Apparatus. Frontiers in Integrative Neuroscience, 7, 66. http://dx.doi.org/10.3389/fnint.2013.00066

[38] Ferrè, E.R., Bottini, G. and Haggard, P. (2012) Vestibular Inputs Modulate Somatosensory Cortical Processing. Brain Structure and Function, 217, 859-864. http://dx.doi.org/10.1007/s00429-012-0404-7

[39] Ferrè, E.R., Bottini, G. and Haggard, P. (2011) Vestibular Modulation of Somatosensory Perception. European Journal of Neuroscience, 34, 1337-1344. http://dx.doi.org/10.1111/j.1460-9568.2011.07859.x

[40] Bottini, G., Paulesu, E., Sterzi, R., Warburton, E., Wise, R.J., Vallar, G., et al. (1995) Modulation of Conscious Experience by Peripheral Sensory Stimuli. Nature, 376, 778-781. http://dx.doi.org/10.1038/376778a0

[41] Vallar, G., Bottini, G., Rusconi, M.L. and Sterzi, R. (1993) Exploring Somatosensory Hemineglect by Vestibular Stimulation. Brain, 116, 71-86. http://dx.doi.org/10.1093/brain/116.1.71 